\title{
Intelligent Bus Monitoring System
}

\author{
Neha Shinde \\ Master of Electronics and Telecommunication \\ VLSI \& Embedded System \\ Dr D Y Patil School Of Engineering, \\ Charholi (Bk), Via Lohgaon, Pune
}

\author{
Saniya Ansari \\ Assistant Professor in Electronics and \\ Telecommunication Dept. \\ Dr D Y Patil School Of Engineering, \\ Charholi (Bk), Via Lohgaon, Pune
}

\begin{abstract}
The real time bus monitoring is to been implemented for public bus (for PMTs in Pune). It includes smart assistant system required for public security and safety. The smart system includes safety from rash driving, accident detection and monitoring facility. It also include user-friendly application for user to track bus on smart their phones. The smart system designed has both online (GPS) and offline (GSM) for user friendly service. It allows user to save its time by acknowledging no. of persons present in the bus as well as no. of seats available in the bus along with the current and next stop acknowledgment with its arrival timings
\end{abstract}

\section{Keywords}

ARM processor, Accelerometer, PIR sensor, RFID unit, GPS/GSM unit.

\section{INTRODUCTION}

Smart city is very much important for developing country now days. The smart life style of today allows us to arrive at our destination as soon as possible. The changing lifestyle is also important with the safety and comfort of vehicle. Development of technology has allowed the concept of an intelligent transport system. Now a day's tremendous growth increases in transport system. The system proposed in this paper states smart way to public transport. Considering all the public issues and problems such as; time, easy of transport, safety and userfriendly environment this system is been designed.

\section{PROPOSED SYSTEM}

Here the design and implementation of smart public transport system for smart cities is proposed. A detailed survey concluded for implementation of various features to the system prototype. Features such as; smart application for user friendly use, GPS/GSM system interface, emergency and bus fail switch, etc included.

The following is detail description of features.

\subsection{Accident detection and acknowledgement}

Now-a-days mostly accidents are record through camera on the street. The main reason to add this feature is to know the exact location of the vehicle system via. GPS/GSM technology. Whenever an accident is occurred or detected, there is a GPS/GSM unit in system which will give information about the location details via. GPS system, after the accident is detected the message will be send to registered police station and at respective area public transport office via. GSM unit through SMS. This will help out to make a better reach-out for the system which needs help.

\subsection{Emergency and bus fail switch}

If an emergency occurs then an emergency (such as women/child safety), and bus fail switch is been pressed according to the condition and then it will sends acknowledgement message via. SMS to help out the victim. The SMS contain bus no. if any help needed HELP ME message or BUS FAIL message.

\subsection{User friendly smart app}

This feature is basically designed for every single user of public transport. Through this app, the people can initialize arrival time and departure time of the bus. They can even track current locations of the bus, and they can pre-acknowledge the travelers in the bus. This will help them save their time.

\subsection{Drunk and drive authentication}

This feature is added to take extra care of public been travelling through transport. If the driver is detected or observed to be drunk, then an acknowledgement via. SMS is sent to PMT office that the driver is been drunk and the driver needs to be changed. The SMS contains bus no. and location of the bus.

\section{RELATED WORK}

The basic idea for offline tracking of vehicle is to be implemented. Following papers are been surveyed to implement the paper.

In SeokJuLee[1], they have proposed system as a bus vehicle tracking for UCSI university, kuala Lumpur, Malaysia. It is implemented for fixed route, providing students with status of bus after specified time interval using LED panel smart phone application. Technology used for proposed system is Ardunio microcontroller Atmega328 based Ardunio UNOR3 microcontroller. Even for GPS, GSM/GPRS module the same controller is used. C programming language is used for software programming, compiling and then saved in microcontroller's flash memory. The testing results in this paper provide; testing in-vehicle device, testing web server and testing smart phone application.

In Pengfei Zhou[2], predicting bus arrival time with mobile phones is given. Technology used is participatory sensing of user. This prototype system is checked different types of smart Android based smart phones and are experimented with the NTU campus travelling shuttle buses as well as Singapore travelling buses over for a 7-week period, then same process followed by London in 4-weeks. The proposed system is solution is more generally available and is energy friendly. The evaluation results suggest that the proposed system gives prediction accuracy compared to the operator initiated for it and GPS support solutions. The prototype system gives bus arrival time with average error of $80 \mathrm{sec}$.

[3], in this paper the bus movement is observed with the help of ruled based decision algorithms and a new theoretical framework and are developed for the system. The ability of the system to work on its own can reduce the manpower required at the monitoring center. Bus drivers will also be more punctual as per the bus schedules that have been established, 
resulting in a more efficient bus circulation system. The results show that the system is able to give important information to the authorities for monitoring and management of the bus system.

In Manali [4] public system for transport is now-a-days mostly used by the users in large cities for travelling on a daily routine. People use buses as a convenient transport to go to their workplaces. But, lack of exact information about the bus arrival time and departure time at bus stoppage often leads the users for waiting at bus stops for longer time. GPS-GSM module technology used to track the location of bus has been discussed and analyzed. But, this incurs high cost. Recently, a smart mobile phone app based on sensing method is been implemented and analyzed which incurs low cost, but mandates the participation of passengers in the process. Based on this, a new technology has been proposed here, as a solution. Which will help the more amount of passenger's participation; it reduces the anxiety of passengers since they know in advance, the arrival time of their bus.

In C.Prabha[5], This paper presents a system of accident detection of vehicle and alerting system with help of SMS to the user defined mobile numbers. It includes GPS tracking system and GSM alerting system based algorithms which are implemented with the help of LPC2148 MCU in embedded system domain. The system can track geographical location of the system and send information automatically through an alert SMS about the accident. Higher sensitivity and accuracy is achieved using this project. EEPROM is interfaced to store the mobile numbers permanently for altering system. This made the project more user-friendly and reliable. The proposed method is verified to be more beneficial for the automotive industry.

In Mashood Mukhtar [6], the paper states that, the system proposed here tracks the location of the system on the user's request as per user require and responds return via SMS. The received message includes longitude value and latitude values of the system that is used to locate the correct location of vehicle system on the Google maps. The vehicle tracking app allows a user to: remotely (without physical contact) switch ON the vehicle's ignition system, remotely (without physical contact) switch OFF the vehicle's ignition system. Some changes were made in which most required change was alteration of the tracking methodology.

\section{DEVLOPMENT OF PROPOSED SYSTEM}

This system is designed for single vehicle as shown in Figure.1. This system consist of ARM cortex, GPS/GSM modem, DC motor, Switches, PIR sensor and a smart phone. The microprocessor based embedded system gives many different features such as high performance, cost sensitive, architectural simplicity and low power consumption.

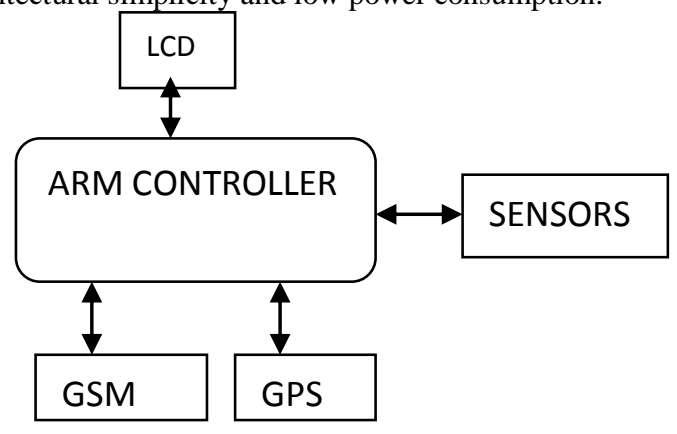

Figure 1: Block Diagram of proposed system
The proposed system has following advantages;

[1] The system has an alcohol sensor which checks the level of alcohol taken by driver through is breath. This helps to prevent accidents caused due to 'drinking and driving'.

[2] The system has an accelerometer used to detect accidents during system is in running mood and an acknowledgement message is been sent to registered number so that quick action can be taken for victims.

[3] The system has two switches, as emergency switch and system fail switch. At every press of switch an acknowledgement message is sent to registered number if any emergency required.

[4] The system also has GPS/GSM module, a miscall alert is given on GSM system through the system, and then a message is sent on registered number in which real-time co-ordinates on the system are available. It helps in off-line tracking of the system.

[5] The system also helps in temperature monitoring of system.

[6] The system also provides RFID authentication for driver.

Also, many additional features make system smart, reliable and public friendly in real time. The following Figure. represents flow for smart app design for user. The smart app designed helps user to track the system at real-time location and even provides no. of persons currently available in the system so that if the no. of persons is more than accepted the user can easily look for another bus and still wait at respective place where he or she is.

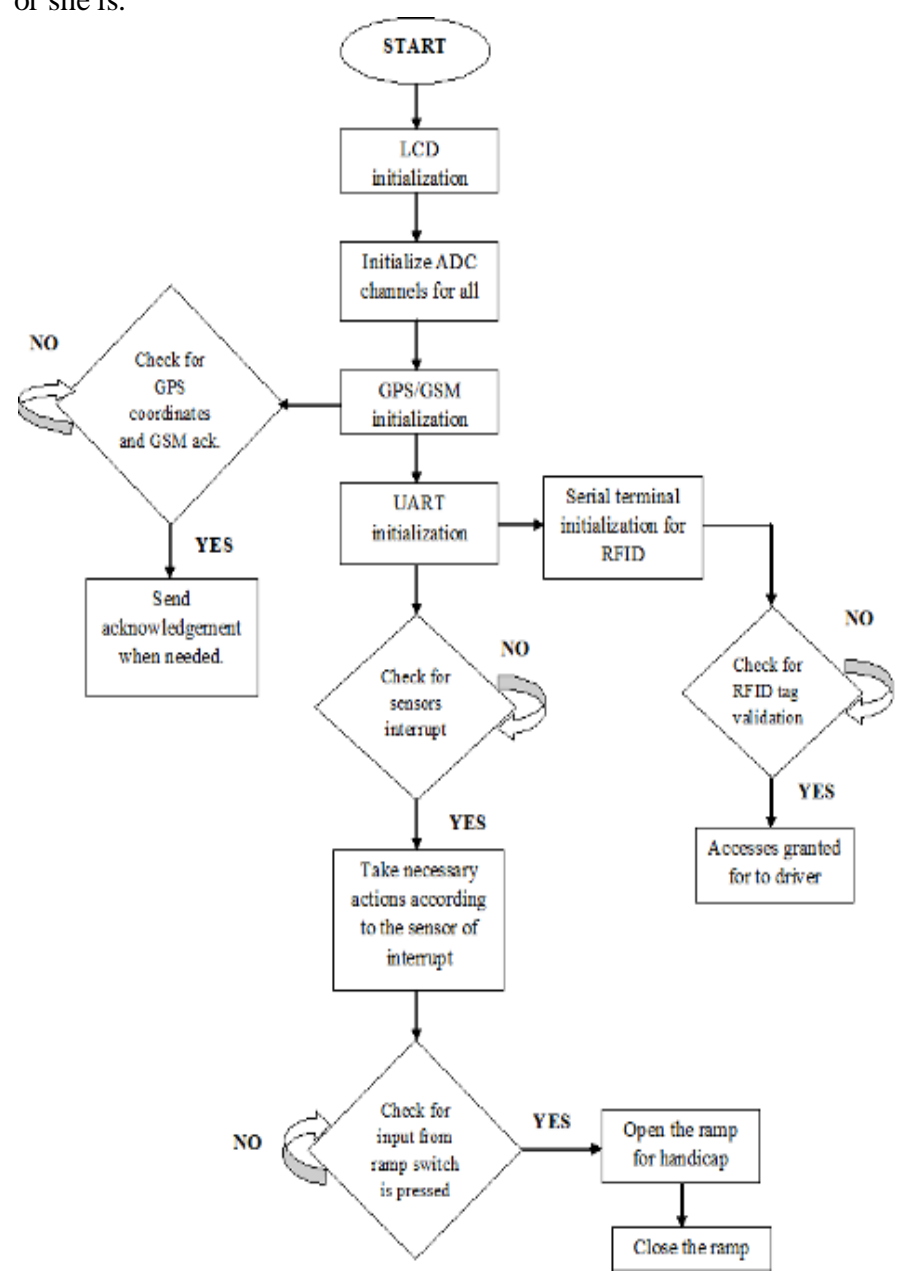

Figure 2: Flowchart for smart app for user. 


\section{HARDWARE AND SOFTWARE SET UP WITH RESULTS}

Top view of system prototype module is as shown in Figure. Here some results of system are shown below. The other safety messages like bus fail, rash driving, alcohol detection, etc are displayed on LCD and SMS acknowledgement is sent via GPS/GSM system as shown below. Also, result of online app designed for system is also shown.

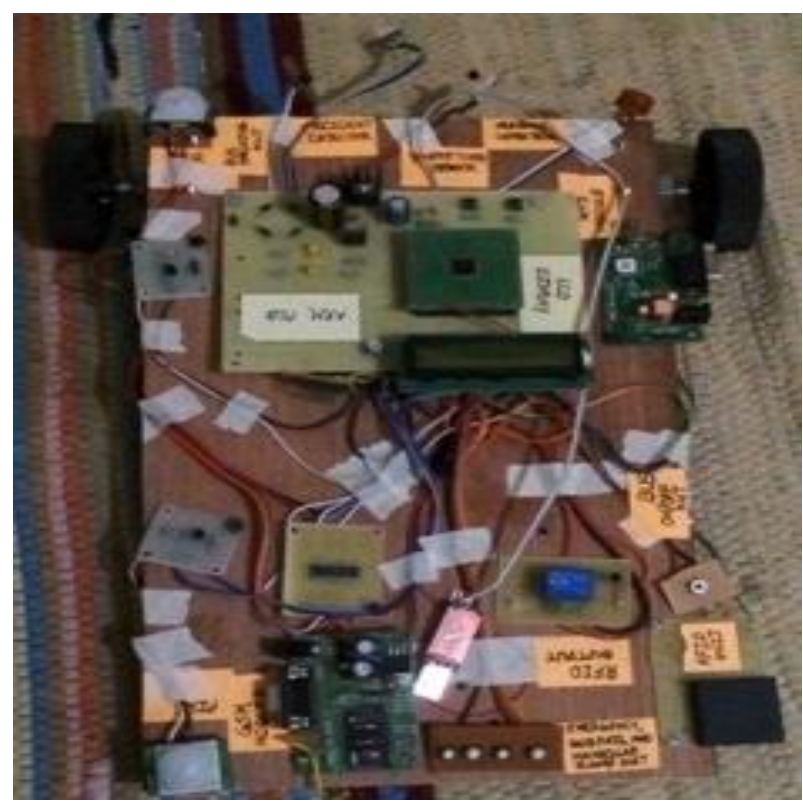

Figure 3: Top view of hardware set up.

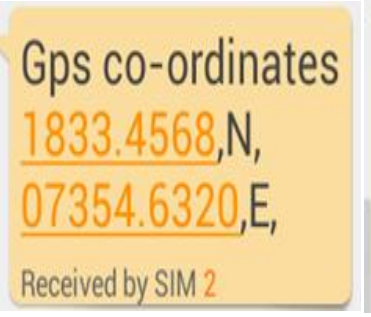

(a)

\section{HELP ME BUS NO-MH12 FS796 Gps co-ordinates ${ }_{m ! m} 0.00,0.0$ $0,060180_{m}, \mathrm{~N} *$ Received by SIM 1}

(c)

DRIVER DRUNK
BUS NO-MH12 F5796
Gps c0-ordinates
$\ldots, 000,0.0$
$0,050180, \ldots, N *$
Received by SIM 1

(b)

BUS FAIL OF
BUS N0-MH12 F5796
AT
Gps co-ordinates
$\frac{2818.905518 \mathrm{~N}}{2521.022217 \mathrm{E}}$
Received by SIM1

(d)

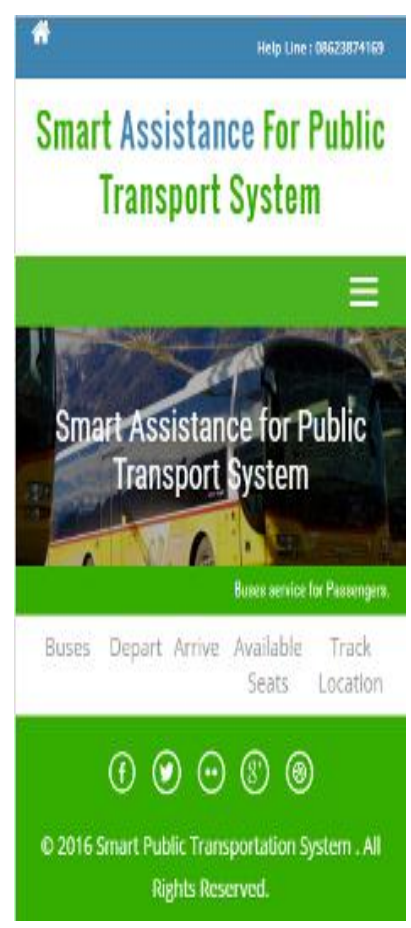

(a)

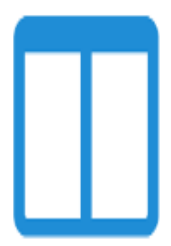

TRACK MY BUS

Search Bus

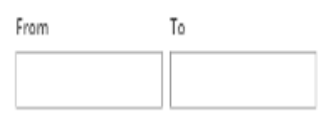

\section{Search Buses}

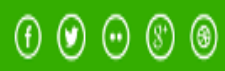

Q 2016 Smart Public Iransportation System. All Rights Resenved.

(b)

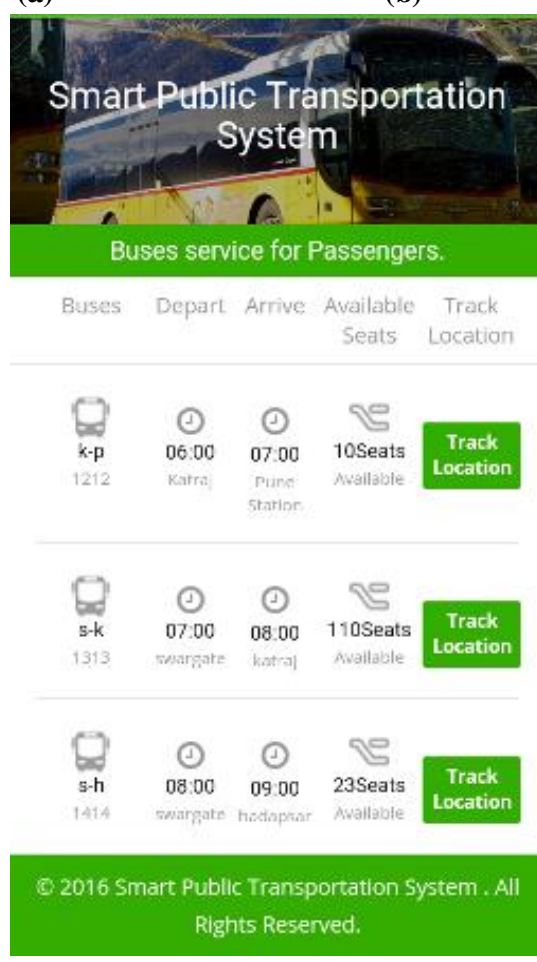

(c)

Figure 5: GUI of user application for system.

Figure 4: GSM results of the system through message on registered number. 


\section{Transportation}
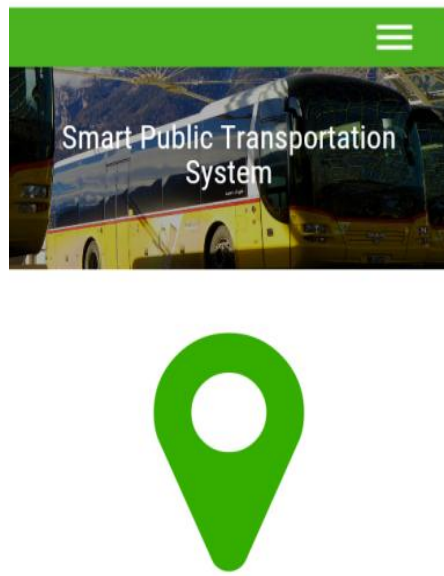

BUS LOCATION

Track Another Bus

(a)

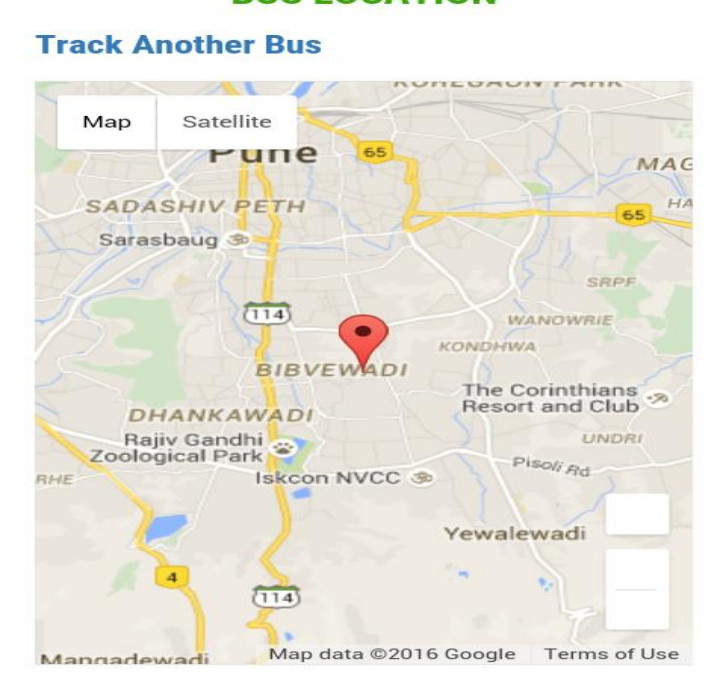

(C) 2016 Smart Public Transportation System . All Rights Reserved.

(b)

Figure 6: Location tracking of system on smart app designed for Public.

\section{CONCLUSION \& FUTURE SCOPE}

The public transport system is expected to be fully automated, transparent, reliable, and convenient. The whole system can be practically implemented for luxury buses, like airport-bounded buses especially at cities in India. The implementation of the system is to be done for bus. The system designed is secured and smartly assisted for public. ARM cortex processor is used as controller to control the whole processing of the system. A system is developed for testing of three sensors i.e. accelerometer, bus fail switch and PIR sensors. The results for tracking of the system through GPS/GSM acknowledgement are taken at real-time. The system can be future implemented for private sectors and in public sectors for trains and luxuries in more quantity. The additional features like upper-dipper, pollution control, fire extinguishers, etc can be added.

\section{ACKNOWLEDGMENTS}

I would like to thank my all the staff members and my guide Prof. Saniya Ansari for guiding me in my project for all time. A special thank you to our HOD and PG coordinator of Dr D Y Patil School Of Engineering, Charholi (Bk), Via Lohgaon, Pune for being moral support through the period of my project study whose help and shared knowledge is the main part of my project.

\section{REFERENCES}

[1] SeoJuLee, Girma Tewolde, Jaerock kwon, "Design and Implementation of Vehicle Tracking System using GPS/GSM/GPRS Technology and Smartphone Application", IEEE world Forum on Internet Of Things (WF-IoT), March 2014, Seoul.

[2] Pengfei Zhou, Student Member, IEEE, Yuanqing Zheng, Student Member, IEEE, and Mo Li, Member, IEEE, "How Long to Wait? Predicting Bus Arrival Time with Mobile Phone Based Participator Sensing", IEEE Transactions on Mobile Computing, vol.13, no. 6, June 2014.

[3] M. A. Hannan, A. M. Mustapha, A. Hussain and H. Basri, "Intelligent Bus Monitoring and Management System", Proceedings of the World Congress onEngineering and Computer Science 2012 Vol II WCECS 2012, October 2426, 2012, San Francisco, USA.

[4] Manali, Najme Zehra Naqvi," Smart Public Transport System Using Mobile phone based sensing"IEEE Indicon 2015 .

[5] C.Prabha, R.Sunitha, R.Anitha, "Automatic Vehicle Accident Detection and Messaging System Using GSM and GPS Modem", International Journal of Advanced Research in Electrical, Electronics and Instrumentation Engineering, July 2014, Vol. 3, Issue 7, pp. 10723-10727.

[6] Mashood Mukhtar,"GPS based Advanced Vehicle Tracking and Vehicle Control System",I.J.Intelligent Systems and Applications, 2015, 03, 1-12 Published Online February 2015 in MECS.

[7] Mr. Pradip Suresh Mane, Prof. Vaishali Khairnar, "Analysis of Bus Tracking System Using Gps on Smart Phones", IOSR Journal of ComputerEngineering (IOSRJCE) e-ISSN: 2278-0661, p- ISSN: 2278-8727Volume 16, Issue 2, Ver. XII (Mar-Apr. 2014), pp. 80-82.

[8] F. Wahl, M. Milenkovic, O. Amft, "A distributed PIRbased approach for estimating people count in office environments", ACTLab, Signal ProcessingSystems, TU Eindhoven, http://actlab.ele.tue.nl. 